\title{
Erratum to: Sensitivity of potential natural vegetation in China to projected changes in temperature, precipitation and atmospheric $\mathrm{CO}_{2}$
}

\author{
Han Wang • Jian Ni • Ian Colin Prentice
}

Published online: 27 March 2011

(C) Springer-Verlag 2011

\section{Erratum to: Reg Environ Change}

DOI 10.1007/s10113-011-0204-2

In the original publication of this article, one of the affiliations for the author Han Wang was missed and is given below.

Graduate University of Chinese Academy of Sciences, 100049 Beijing, China.

The online version of the original article can be found under doi:10.1007/s10113-011-0204-2.

H. Wang $(\varangle) \cdot$ J. Ni

State Key Laboratory of Vegetation and Environmental Change, Institute of Botany, Chinese Academy of Sciences,

Xiangshan Nanxincun 20, 100093 Beijing, China

e-mail: angwanh@gmail.com

H. Wang · I. C. Prentice

Department of Biological Sciences, Macquarie University,

North Ryde, NSW 2109, Australia

H. Wang

Graduate University of Chinese Academy of Sciences,

100049 Beijing, China

J. Ni

Alfred Wegener Institute for Polar and Marine Research,

Telegrafenberg A43, 14473 Potsdam, Germany

I. C. Prentice

Grantham Institute and Division of Biology, Imperial College,

Silwood Park, Ascot SL5 7PY, UK 